\title{
Duodenal calcium outputs in health and pancreatic disease*
}

\author{
P T REGAN, $\dagger$ J-R MALAGELADA, AND E P DiMAGNO
}

From the Gastroenterology Unit, Mayo Clinic and Mayo Foundation, Rochester, Minnesota, USA

SUMmARY To investigate the relationship between the duodenal outputs of calcium and diseases of the pancreas, we measured calcium secretion into the duodenum (during saline perfusion and after stimulation with an intravenous infusion of cholecystokinin (CCK) or secretin) in healthy controls, patients with chronic alcoholic or idiopathic pancreatitis, and patients with pancreatic cancer. The effects of acute and chronic hypercalcaemia and previous cholecystectomy were also studied. Our results indicate a characteristic increase in duodenal calcium outputs in response to CCK in chronic pancreatitis which is unaffected by the level of serum calcium, aetiology of the pancreatitis, previous cholecystectomy, and the presence or absence of radiological pancreatic calcifications. Although unproven, indirect observations support a pancreatic source for the increased calcium secretion. As we measured the outputs of calcium into the duodenum, previously described increases in calcium concentration are not merely a reflection of reduced volume secretion in chronic pancreatitis. Duodenal calcium outputs were significantly reduced in patients with cancer of the pancreas.

Disturbances of calcium metabolism have often been linked to inflammatory diseases of the pancreas. Patients with hyperparathyroidism and hypercalcaemia appear to develop acute and chronic pancreatitis more frequently than expected. ${ }^{\mathbf{2}}$ Histological and radiological calcification of the pancreas is a frequent finding in chronic pancreatitis, particularly when secondary to chronic alcoholism. ${ }^{3}$ However, the relationship, if any, between disturbances of serum and pancreatic juice calcium levels and pancreatitis remains unclear.

Previous investigators have documented high concentrations of calcium in the duodenal contents of patients with chronic pancreatitis. ${ }^{4-7}$ However, as total secretory volumes are reduced in exocrine pancreatic disease, ${ }^{8}$ calcium concentration may not reflect the actual status of pancreatic calcium secretion. Furthermore, the ultimate source of duodenal calcium secretion-that is, hepatobiliary or pancreatic-is unknown.

Therefore, using previously validated intestinal

*Supported in part by Grant No. AM 6908 from the National Institutes of Health and by Grant No. CP 55660 from the National Cancer Institute, Bethesda, MD, USA. Presented in part at the National meeting of the American Pancreatic Association, Chicago, IL, November 1977.

†Address for reprint requests: Dr P T Regan, Mayo Clinic, Rochester, MN 55901, USA.

Received tor publication 7 January 1980 perfusion methodology, the aims of the present study were (1) to measure duodenal calcium outputs in healthy individuals and in patients with pancreatic disease; (2) to determine the effects of acute and chronic hypercalcaemia on calcium delivery into the duodenum; and (3) to determine the effects of prior cholecystectomy on intraduodenal calcium content.

\section{Methods}

Duodenal outputs of calcium were measured in 124 subjects. Forty-six patients showed no evidence of exocrine pancreatic disease and were divided into four groups: (1) healthy controls $(n=17)$; (2) healthy controls during an intravenous infusion of calcium chloride resulting in a serum calcium averaging $2 \mathrm{mg} / \mathrm{dl}$ greater than normal $(\mathrm{n}=9)$; (3) healthy controls at least six months after cholecystectomy $(n=5)$; and (4) 'disease controls'; patients with intraabdominal disorders not involving the pancreasthat is, cholelithiasis, abdominal lymphoma, ovarian carcinoma-confirmed at laparotomy $(n=15)$. Exocrine pancreatic function in response to intravenous cholecystokinin $(\mathrm{CCK})^{9}$ was normal in each instance. The hypercalcaemic ${ }^{10}$ and disease control ${ }^{11}$ patients have been included in previous publications.

Fifty-six patients with documented chronic pancreatitis were studied. The diagnosis was confirmed by an abnormal pancreatic function test ${ }^{9}$ in 
the presence of pancreatic calcifications or at laparotomy and four subgroups were included: (1) alcoholic chronic pancreatitis with $(n=13)$ or without $(n=9)$ radiologically visible calcifications; (2) idiopathic chronic pancreatitis with $(n=11)$ or without $(n=13)$ pancreatic calcification; (3) calcific alcoholic chronic pancreatitis with prior cholecystectomy $(\mathrm{n}=8)$; and (4) alcoholic chronic pancreatitis with coexistent chronic hypercalcaemia, in each case due to hyperparathyroidism $(n=2)$. The groups were equivalent in regard to age, sex, and duration of pancreatic disease.

Finally, we measured duodenal calcium secretion in 22 patients with subsequent surgically proven adenocarcinoma of the pancreas. Five of these subjects had had a previous cholecystectomy and two additional patients were hypercalcaemic at the time of the study.

\section{PERFUSION PROCEDURE}

Intubation and intestinal perfusion were performed as previously described. ${ }^{912}$ After an overnight fast gastric and duodenal tubes were fluoroscopically positioned. The gastric tube was a Salem sump tube and its aspiration site was located in the antrum for constant removal of gastric secretions. The duodenal tube had a perfusion site at the ampulla of Vater where polyethylene glycol $(5 \mathrm{~g} / \mathrm{l})$ in normal saline $(0 \cdot 15 \mathrm{M})$ was perfused at a rate of $10 \mathrm{ml} / \mathrm{min}$. An aspiration site was localised $20 \mathrm{~cm}$ distally near the ligament of Treitz.
Each subject was studied for at least two hours. During the first hour, isotonic saline was infused intravenously and into the duodenum (control period). During the second hour, 20\% CCK (Karolinska Institute) was administered as a constant intravenous infusion at a rate of 0.25 CrickHarper-Raper units $/ \mathrm{kg} / \mathrm{h}$ which produces maximal pancreatic stimulation. In addition, approximately half of the subjects were also given an intravenous infusion of secretin (Karolinska 2 units $/ \mathrm{kg} / \mathrm{h}$ ) for two hours before the administration of cholecystokinin.

Aliquots of duodenal contents were collected continuously by siphonage and pooled over ice at 20 minute intervals.

\section{ANALYTICAL STUDIES}

Lipase, trypsin, and polyethylene glycol concentrations were determined by previously described methods. ${ }^{9101213}$ Calcium concentration was measured by atomic absorption spectroscopy. ${ }^{14}$ Outputs of lipase, trypsin, and calcium were calculated by the use of marker concentrations as previously reported..$^{9-13}$

The data were statistically analysed with the Rank sum test.

\section{Results}

DUODENAL CALCIUM OUTPUTS

Compared with control subjects, duodenal calcium

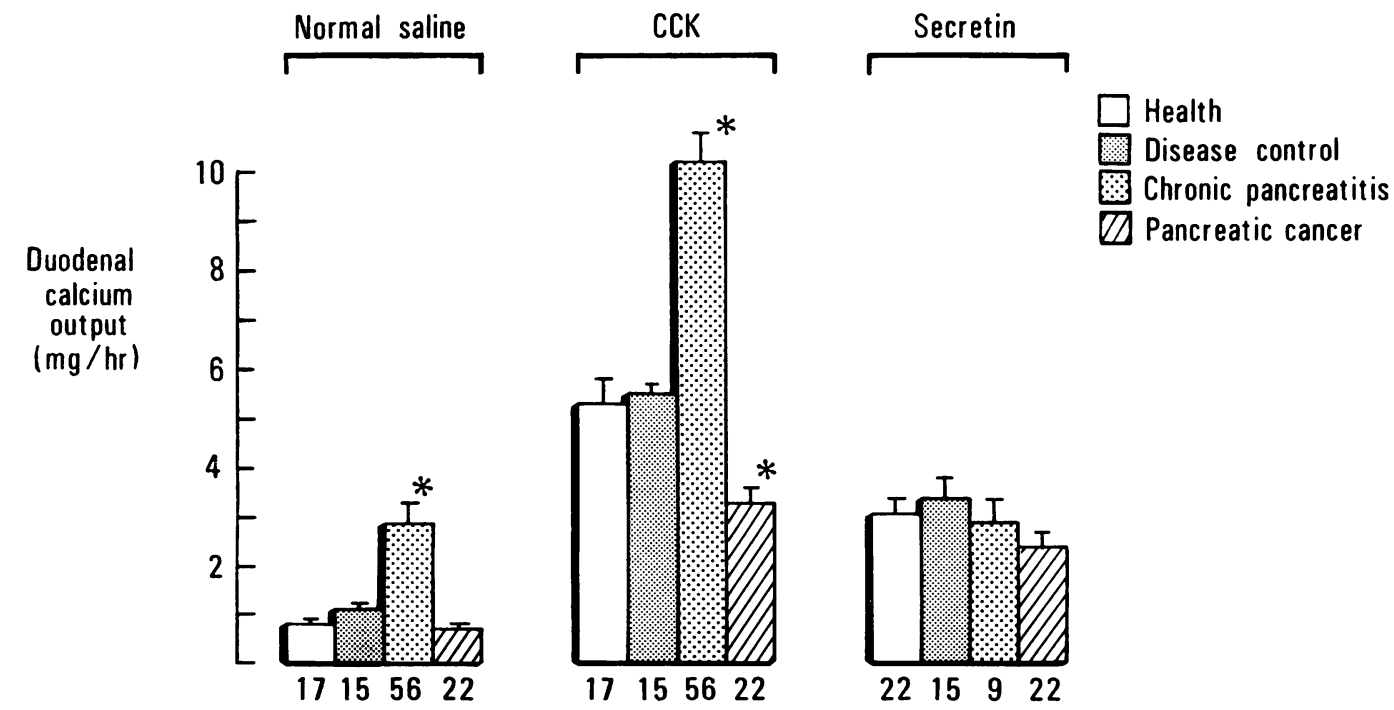

Fig. 1 Duodenal calcium outputs $(\mathrm{mg} / \mathrm{h})$ in health and pancreatic disease during saline infusion and during stimulation with $C C K(0.25 \mathrm{CHR}$ units/ $\mathrm{kg} / \mathrm{h})$ and secretin $(2$ units/kg/h). Mean $( \pm S E M)$ values for each group are depicted. ${ }^{*} \mathrm{P}<0.01$ compared with health and disease control. 


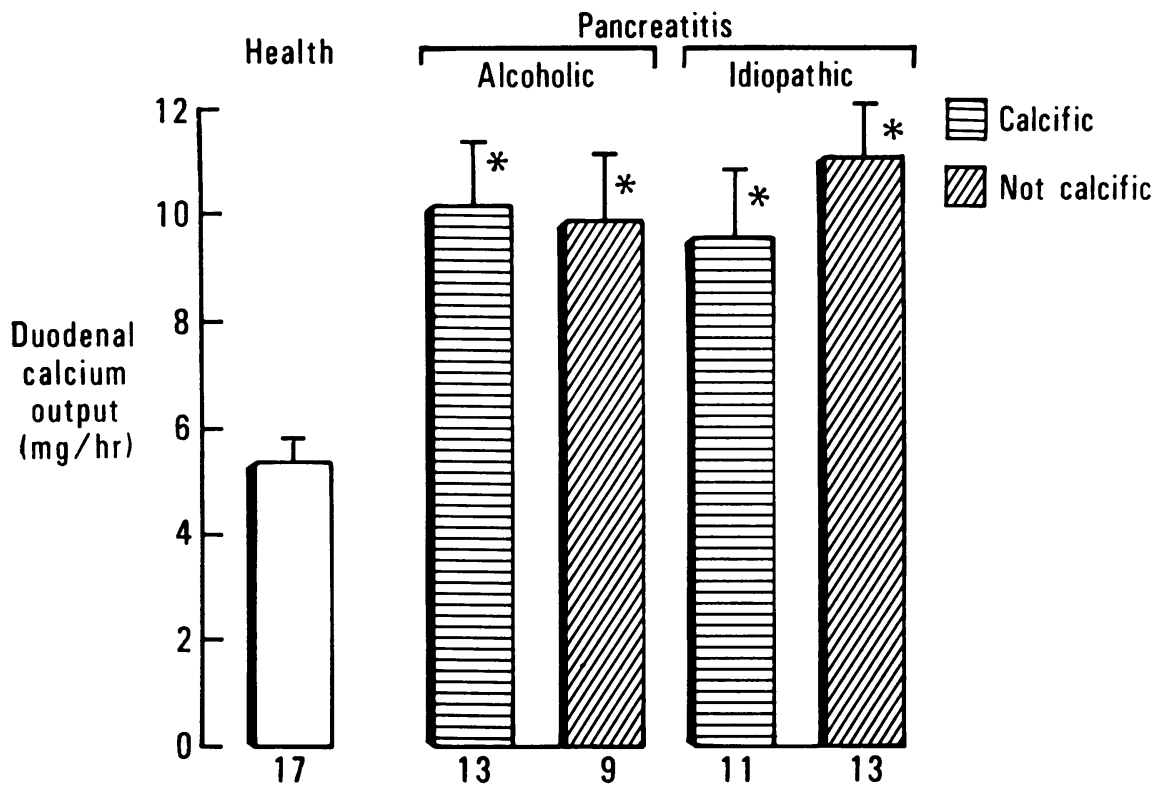

Fig. 2 Duodenal calcium outputs $(\mathrm{mg} / \mathrm{h})$ during CCK infusion $(0 \cdot 25 \mathrm{CHR}$ units $/ \mathrm{kg} / \mathrm{h})$ in health and the subgroups of chronic pancreatitis: alcoholic or idiopathic with or without radiological calcifications. Mean ( $\pm S E M)$ values for each group are depicted. ${ }^{*} \mathrm{P}<0.01$ compared with health.

outputs were increased in chronic pancreatitis both during saline infusion and CCK stimulation $(\mathbf{P}<0.01)$, and decreased in patients with pancreatic cancer $(\mathbf{P}<0.01)$ in response to CCK (Fig. 1). Values during CCK infusion were not affected by the prior administration of secretin. Calcium outputs after secretin were slightly increased over control values in all groups except chronic pancreatitis.

The higher duodenal calcium outputs after CCK in chronic pancreatitis were independent of aetiology or macroscopic pancreatic calcification (Fig. 2). Similar results were observed for calcium secretion during intraduodenal saline infusion (control period) in the subcategories of pancreatitis (data not shown).

EFFECTS OF HYPERCALCAEMIA (Table)

In healthy subjects, acutely induced hypercalcaemia caused a small but significant rise in duodenal calcium content during the control hour only $(\mathrm{P}<0.05)$.

In the four patients with coexistent pancreatic disease and chronic hypercalcaemia, both control and CCK-stimulated calcium outputs were similar to the values observed in normocalcaemic patients.

EFFECT OF PRIOR CHOLECYSTECTOMY

In health, chronic pancreatitis, and pancreatic cancer, the presence or absence of the gallbladder did not affect the values for duodenal calcium in response to any stimulus (results for CCK only shown in Fig. 3).

CORRELATIONS OF RESULTS

In chronic pancreatitis, no correlations were ob-

Table Effects of hypercalcaemia on duodenal calcium outputs in health and in pancreatic disease

\begin{tabular}{|c|c|c|c|c|}
\hline & \multicolumn{4}{|c|}{ Duodenal calcium outputs ( $\mathrm{mg} / \mathrm{h})$} \\
\hline & \multicolumn{2}{|l|}{ Control } & \multicolumn{2}{|l|}{$C C K$-stimulated } \\
\hline & Normo- & Hyper- & Normo- & Hyper \\
\hline $\begin{array}{l}\text { Health } \\
\text { Chronic pancreatitis } \\
\text { Pancreatic cancer }\end{array}$ & $\begin{array}{l}0 \cdot 8 ; 0 \cdot 3-1 \cdot 3(17) \\
2 \cdot 1 ; 1 \cdot 0-8 \cdot 1(54) \\
0 \cdot 7 ; 0 \cdot 4-1 \cdot 4(20)\end{array}$ & $\begin{array}{l}1 \cdot 0 ; 0 \cdot 5-2 \cdot 8(9)^{*} \\
2 \cdot 8,4(2) \\
0 \cdot 8,0 \cdot 4(2)\end{array}$ & $\begin{array}{c}5 \cdot 3 ; 3 \cdot 0-7 \cdot 6(17) \\
10 \cdot 1 ; 3 \cdot 8-19 \cdot 2(54) \\
3 \cdot 0 ; 1 \cdot 5-7 \cdot 7(20)\end{array}$ & $\begin{array}{l}4 \cdot 6: 3 \cdot 0-7 \cdot 8(9) \\
8 \cdot 5.10 \cdot 4(2) \\
2 \cdot 6,3 \cdot 2(2)\end{array}$ \\
\hline
\end{tabular}

Values represent medians and ranges and numbers of subjects in each group are in parentheses. In groups of only two subjects, absolute values are listed.

${ }^{*} \mathbf{P}<0.05$ compared with normocalcaemic health. 

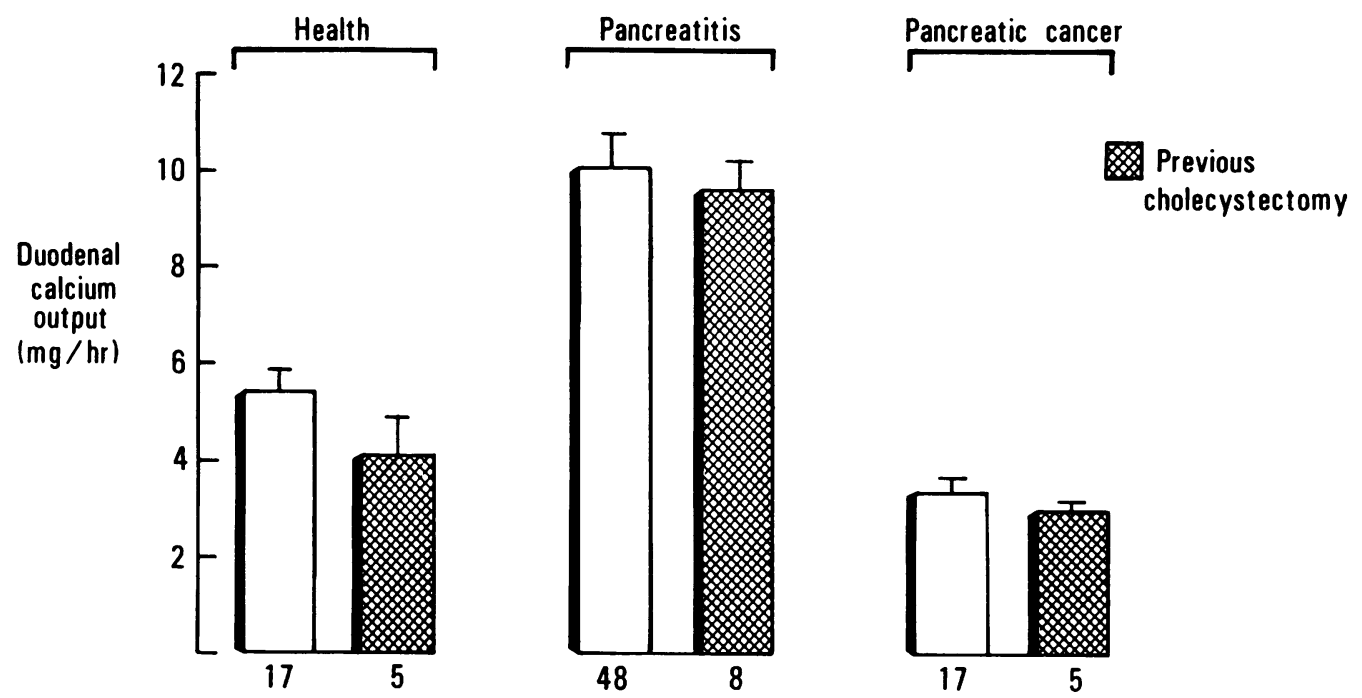

Fig. 3 Duodenal calcium outputs $(\mathrm{mg} / \mathrm{h})$ in health, chronic pancreatitis and pancreatic cancer during CCK infusion $(0 \cdot 25 \mathrm{CHR}$ units $/ \mathrm{kg} / \mathrm{h})$. Subjects with and without a prior cholecystectomy are depicted for each group. Mean $( \pm S E M)$ values are shown.

served between duodenal recovery of calcium and pancreatic lipase or trypsin after CCK or faecal fat excretion $(P>0.05)$.

\section{Discussion}

Our studies reveal that chronic pancreatitis is associated with a significant increase in the duodenal outputs of calcium which is independent of the level of serum calcium, aetiology of the pancreatitis, previous cholecystectomy, and the presence or absence of radiological pancreatic calcifications.

In previous human studies, high calcium concentrations in the duodenal contents or pancreatic fistulous effluent of patients with chronic pancreatitis have been reported. ${ }^{4-7}$ We now show that duodenal outputs of the calcium cation are raised in pancreatitis. Thus the previously described high calcium concentrations are not merely a reflection of reduced volume secretion by the diseased pancreas but represent an increase in the absolute amount of calcium flux into the duodenum.

Others have described increased duodenal calcium concentrations in patients with pancreatic carcinoma. ${ }^{4}$ In contrast, we have demonstrated a reduction in calcium outputs in a large group of patients with pancreatic cancer which presumably reflects reduced volume secretion due to ductal obstruction. ${ }^{15}$ Therefore, increased outputs of duodenal calcium are not a uniform feature of all types of pancreatic disease but, rather, are restricted to chronic pancreatitis.
In this study, a constant intravenous infusion of relatively pure secretin (Karolinska Institute) did not increase duodenal calcium outputs above control values in patients with chronic pancreatitis. The stimulatory effect of secretin observed by others $^{56}$ may well be related to the method of administration (intravenous bolus) and the use of a secretin preparation (Boots) which contains significant amounts of CCK.

We are unable to state with certainty the origin of the raised content of duodenal calcium in chronic pancreatitis, but indirect observations strongly suggest a pancreatic source. Calcium in hepatic or gallbladder bile could alter the duodenal outputs of this cation. However, in our study, CCK produced a rise in duodenal calcium outputs in both health and chronic pancreatitis independent of the presence or absence of the gallbladder. As the outputs of duodenal bile acid in patients after cholecystectomy are stable and unaffected by exogenous administration of $\mathrm{CCK},{ }^{16}$ it seems unlikely that hepatic bile is the source of the increased content of duodenal calcium that is observed in chronic pancreatitis. Only future investigation of the concentration and outputs of calcium in pure pancreatic juice (as obtained by endoscopic retrograde pancreatography), ${ }^{8}$ can settle this question. It should be mentioned that the CCK preparation (Karolinska) used in these studies is impure and contains other gastrointestinal hormones which might play a role in stimulating duodenal calcium secretion.

There are conflicting reports as to the relationship 
between serum and duodenal calcium. Some experimental and human studies have noted high duodenal or pancreatic calcium concentrations during induced or spontaneous hypercalcaemia, ${ }^{17} 18$ and, in some instances, pancreatic calcium concentration exceeded that in the serum..$^{18}$ Others have observed no relationship between serum and pancreatic calcium. ${ }^{19}$ In our studies, small but significant rises in outputs of control duodenal calcium occurred in healthy subjects made acutely hypercalcaemic. However, duodenal calcium outputs after CCK were not related to the level of serum calcium in health or in any of the disease groups examined.

Raised levels of calcium in pancreatic secretions could certainly be related to the production of pancreatitis. Calcium is known to be an integral part of the amylase molecule, ${ }^{20}$ appears to accelerate activation of trypsinogen, ${ }^{21}$ and calcium salts may precipitate in alkaline media such as are normally found in the pancreatic ducts. ${ }^{22}$ Intrapancreatic activation of trypsinogen coupled with pancreatic ductal obstruction secondary to calcified stones could result in pancreatic injury. Support for this hypothesis has been obtained in the recent demonstration by Sarles and his colleagues of microprecipitation of a calcium protein matrix in the early stages of experimental alcoholic pancreatitis in dogs. ${ }^{23}$ Whether excessive pancreatic secretion of calcium is an antecedent event is unknown.

In summary, raised outputs of duodenal calcium are a characteristic feature of idiopathic and alcoholic chronic pancreatitis, most probably originate from the pancreas, and may be related to pancreatic injury.

\section{References}

${ }^{1}$ Mixter CG, Keynes WM, Cope O. Further experience with pancreatitis as a diagnostic clue to hyperparathyroidism. $N$ Engl J Med 1962; 266: 265-72.

${ }^{2}$ Kurlander DJ, Raskin HF, Kirsner JB. Co-existence of pancreatitis and hyperparathyroidism. Ann Intern Med 1963; 58: 1013-16.

${ }^{3}$ Owens JL Jr, Howard JM. Pancreatic calcification: a late sequel in the natural history of chronic alcoholism and alcohol pancreatitis. Ann Surg 1958; 147: 326-38. ${ }^{4}$ Gullo L, Sarles H, DeBarros C, et al. Pancreatic secretion of calcium in healthy subjects and various diseases of the pancreas. Rendic Gastroenterol 1974; 6: 35-44. ${ }^{5} \mathrm{Hansky}$ J. Calcium content of duodenal juice. Am J Dig Dis 1967; 12: 725-33.

${ }^{6}$ Nimmo J, Finlayson NDC, Smith AF, et al. The production of calcium and magnesium during pancreatic function tests in health and disease. Gut 1970; 11: 163-6. 'Warwick RRG, Tothill P, Percy-Robb IW, Shearman, DJC. The calcium concentration in pancreatic secretion in chronic pancreatitis and carcinoma of the pancreas. Scand J Gastroenterol 1973; 8: 301-5.

${ }^{8}$ Kawanishi H, Sell JE, Pollard HM. Combined endoscopic pancreatic fluid collection and retrograde pancreatography in the diagnosis of pancreatic cancer and chronic pancreatitis. Gastrointest Endosc 1975; 22: $82-5$.

${ }^{9}$ DiMagno EP, Go VLW, Summerskill WHJ. Relations between pancreatic enzyme outputs and malabsorption in severe pancreatic insufficiency. $N$ Engl J Med 1973; 288: 813-5.

${ }^{10}$ Malagelada JR, Holtermuller KH, Sizemore GW, Go VLW. The influence of hypercalcemia on basal and cholecystokinin-stimulated pancreatic, gallbladder, and gastric functions in man. Gastroenterology 1976; 71 : 405-8.

${ }^{11}$ DiMagno EP, Malagelada JR, Taylor WF, Go VLW. A prospective comparison of current diagnostic tests for pancreatic cancer. N Engl J Med 1977; 297: 737-42.

${ }^{12} \mathrm{Go}$ VLW, Hofmann AF, Summerskill WHJ. Simultaneous measurements of total pancreatic, biliary and gastric outputs in man using a perfusion technique. Gastroenterology 1970; 58: 321-8.

${ }^{13}$ Malagelada JR, Lonstreth GF, Summerskill WHJ, Go VLW. Measurement of gastric functions during digestion of ordinary solid meals in man. Gastroenterology 1976; 70: 203-10.

${ }^{14}$ Slavin W. Atomic absorption spectroscopy. New York: Interscience Publisher, 1968.

${ }^{15}$ DiMagno EP, Malagelada JR, Go VLW. The relationships between pancreatic ductal obstruction and pancreatic secretion in man. Mayo Clin Proc 1979; 54: $157-62$.

${ }^{16}$ Malagelada JR, Go VLW, Summerskill WHJ. Differing sensitivities of gallbladder and pancreas to cholecystokinin-pancreoxymin (CCK-PZ) in man. Gastroentero$\log y$ 1973; 64: 950-4.

${ }^{17}$ Goebell H, Steffen C, Baltzer G, and Bode C. Stimulation of pancreatic secretion of enzymes by acute hypercalcaemia in man. Eur J Clin Invest 1973; 3: 98-104.

${ }^{18}$ Herskovic T, Wakim KG, Bartholomew LG, Cain JC, Jones JD. Relationship of calcium in the serum to that in the pancreatic secretion in normal and hypercalcemic states. Surgery 1975; 58: 530-4.

${ }^{19}$ McPherson RC, Pace WG. Calcium excretion by the pancreas in hypercalcemia. Surg Forum 1961; 12: $372-4$.

${ }^{20}$ Stein EA, Hsiu J, Fischer EH. Alpha-amylases as calcium-metalloenzymes. I. Preparation of calcium-free apoamylases by chelation and electrodialysis. Biochemistry 1964; 3: 56-61.

${ }^{21}$ Haverback BJ, Dyce B, Bundy H, Edmondson HA. Trypsin, trypsinogen and trypsin inhibitor in human pancreatic juice: mechanism for pancreatitis associated with hyperparathyroidism. Am J Med 1964; 29: 424-33.

${ }^{22}$ Gross JB. Some recent developments pertaining to pancreatitis. Ann Intern Med 1958; 49: 796-819.

${ }^{23}$ Sarles H. Chronic calcifying pancreatitis-chronic alcoholic pancreatitis. Gastroenterology 1974; 66: 604-16. 


\section{Notes and activities}

\section{BSG Autumn Meeting, Reading}

The autumn meeting of BSG was held on the campus of the University of Reading on 24-26 September, with Dr B E Morson as President, and Dr P B Cotton as Vice-President Endoscopy. The local secretary, Mr R Faber, and his team deserve our thanks for an efficiently organised scientific and social programme. In addition to a teaching session devoted to tropical disorders and interventional radiology, the first day offered meetings of the Liver Club, Pathologists' Group, Radiologists' Group, Endoscopy Assistants' and the Royal College of Nursing Group and an inaugural meeting of the Basic Science Group. There was also a joint Endoscopy/Pathology symposium at which Professor G N Tytgat gave the Endoscopy Foundation Lecture on 'Endoscopic management of dysphagia'. On the following days 146 papers were presented and additional work was discussed at a poster session. Professor A E Read was installed as the new President of BSG and Professor C G Clark was chosen as President Elect.

\section{The Fothergillian Medal and Harveian Oration}

Those two high distinctions were bestowed by the medical profession this year on Sir Francis Avery Jones. The Fothergillian Medal was awarded to him by the Medical Society of London. The Royal College of Physicians has chosen him this year as their Harveian Orator and he took this opportunity to present a masterly survey of the growth of gastroenterology from Harvey's day to the present time. We offer Sir Francis our warmest congratulations.

\section{Journal of Autonomic Pharmacology}

The Journal of Autonomic Pharmacology is to appear in Autumn 1980 and will be concerned with the effects of drugs on the mammalian autonomic nervous system. The editor is M D Day, PhD, (Research Laboratories, Reckitt and Colman Ltd, Pharmaceutical Division, Hull). It will be published by Galen Press, Medical and Scientific Publishers, PO Box 2, North Ferriby, North Humberside HU14 3AA, UK, from whom details may be obtained.
Falk-Symposium, Nos 30-32 An Intestinal Week will be held at Titisee, Black Forest, W. Germany, from 24-31 May 1981. It will include the Second International Conference on Intestinal Adaptation (24-26 May), Colonic Carcinogenesis (27-29 May), and Colon and Nutrition (29-31 May). Details may be obtained from FalkFoundation e.V., Habsburgerstr. 81, D-7800 Friburg i. Br., W. Germany.

\section{Second International Symposium on \\ Mucus in Health and Disease}

This symposium will be held at Manchester University, England, from 31 August to 4 September 1981. Organising Committee: Eric Chantler, Department of Obstetrics and Gynaecology, and James Elder, Department of Surgery, Manchester University, Manchester, UK.

\section{Eighth International Symposium on}

\section{Gastrointestinal Motility}

The 8th International Symposium on Gastrointestinal Motility will take place in Konigstein near Frankfurt am Main, F.R. Germany, from 7 to 11 September 1981. The organisers invite contributions, especially with clinical relevance. Abstracts, not to exceed 250 words, should be sent to Dr M Wienbeck, Department of Internal Medicine $D$, University Hospitals, Moorenstr. 5, D-4000 Dusseldorf, F.R. Germany, before 1 March 1981.

\section{Books}

The Mast Cell: its role in health and disease Edited by $\mathbf{J}$ Pepys and $\mathbf{A}$ M Edwards. Proceedings of an International Symposium, Davos, Switzerland, April 1979. (Pp. 873. Illustrated). Pitman Medical: England. 1979.

To review a book of such length on a subject like the mast cell is beyond the capacity of any ordinary reviewer. The amount of information is too great for anyone to claim honestly that he has read it from end to end.

This publication contains eight parts on, respectively, the mast cell, the mode of action of sodium cromoglycate, respiratory disease, food allergy, eye disease, skin disease, inflammatory bowel disease, and ENT diseases. The content of the presentations varies widely, some including large amounts of experimental data and others contenting themselves with reviews. The quality of the presentations is equally variable. Generalisation may be a little unfair, but the descriptions of basic scientific work tend to be of higher quality and of more sober judgement than some of the clinical work. Thus there is a tendency of some to claim promising results despite the lack of full analyses, and to found opinions upon uncontrolled observations.

This is not a book from which to obtain a balanced judgement of the role of the mast cell in health and disease, nor could any conference proceedings be expected to be so. It does, however, present a great variety of evidence, some significant and some not so important, about mast cell function and dysfunction.

This is a book for the interested individual to borrow, but not necessarily to buy.

M J S LANGMAN

\section{Correction}

Duodenal calcium outputs in health and pancreatic disease, by P T Regan, J-R Malagelada, and E P DiMagno (Gut $1980,21,614-18$.) The dose of cholecystokinin used in these studies was 0.25 CHR $\mathrm{U} / \mathrm{kg} / \mathrm{min}$, not $0.25 \mathrm{CHR} \mathrm{U} / \mathrm{kg} / \mathrm{h}$. 